\title{
Probing Conformational Changes of Ubiquitin by Host-Guest Chemistry Using Electrospray Ionization Mass Spectrometry
}

\author{
Jong Wha Lee, ${ }^{1}$ Sung Woo Heo, ${ }^{2}$ Shin Jung C. Lee, ${ }^{1}$ Jae Yoon Ko, ${ }^{1}$ Hyungjun Kim, ${ }^{3}$ \\ Hugh I. Kim ${ }^{1}$ \\ ${ }^{1}$ Department of Chemistry, Pohang University of Science and Technology, Pohang, Gyeongbuk, Korea \\ ${ }^{2}$ Division of Metrology for Quality of Life, Korea Research Institute of Standards and Science, Daejeon, Korea \\ ${ }^{3}$ Graduate School of EEWS, Korea Advanced Institute of Science and Technology, Daejeon, Korea
}

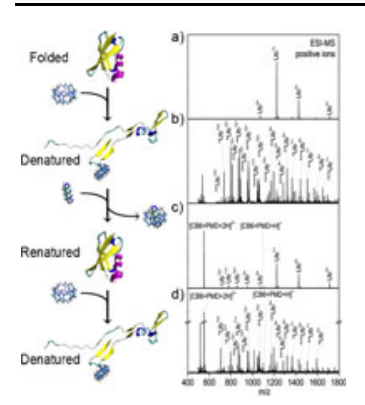

conformational change mechanisms of $\mathrm{Ub}$ by host-guest chemistry with $\mathrm{CB}[6]$ compared with solvent-driven conformational change of $\mathrm{Ub}$. Additional CID study reveals that $\mathrm{CB}[6]$ is bound only to $\mathrm{Lys}_{48}$ and $\mathrm{Lys}_{63}$ in low charge state $(+7)$ complex. MD simulation studies reveal that the high charge state complexes are attributed to the CB[6] bound to $\mathrm{Lys}_{11}$. The complexation prohibits salt bridge formation between $\mathrm{Lys}_{11}$ and $\mathrm{Glu}_{34}$ and induces conformational change of $\mathrm{Ub}$. This results in formation of high charge state complexes in the gas phase. Then, by utilizing stronger host-guest chemistry of $\mathrm{CB}[6]$ with pentamethylenediamine, refolding of $\mathrm{Ub}$ via detaching $\mathrm{CB}[6]$ from the protein is performed. Overall, this study gives an insight into the mechanism of denatured $\mathrm{Ub}$ ion formation via host-guest interactions with $\mathrm{CB}[6]$. Furthermore, this provides a direction for designing function-controllable supramolecular system comprising proteins and synthetic host molecules. Key words: Ubiquitin, Conformational change, Supramolecular chemistry, Host-guest chemistry, Cucurbit[6] uril, Electrospray ionization, Collision-induced dissociation

Received: 8 August 2012/Revised: 4 September 2012/Accepted: 8 September 2012/Published online: 11 December 2012

\section{Introduction}

$\mathrm{U}$ nderstanding structural dynamics of proteins is still a challenging field of study. Several analytical methods (e.g., single molecule spectroscopy [1], sum frequency generation spectroscopy [2], nuclear magnetic resonance spectroscopy [3], etc.) have been applied to reveal information of the dynamic states of proteins. Electrospray ioniza-

Jong Wha Lee and Sung Woo Heo contributed equally to this work.

Electronic supplementary material The online version of this article (doi:10.1007/s13361-012-0496-6) contains supplementary material, which is available to authorized users.

Correspondence to: Hugh I. Kim; e-mail: hughkim@postech.edu tion mass spectrometry (ESI-MS) has also been widely used for examining protein structures due to its unique advantage of isolating and characterizing particular components in the mixture [4-10].

Ubiquitin (Ub) is a highly conserved small globular protein with 76 amino acid residues. This small protein performs essential functions in eukaryotes through conjugation and ligation to the substrate protein $[11,12]$. The seven lysine (Lys) residues and $\mathrm{N}$-terminus of $\mathrm{Ub}$ are involved in polyubiquitination events [13-15], and differently linked polyubiquitin chains exhibit distinct functions [16]. The structure of $\mathrm{Ub}$ is well-characterized both in the solution phase and the gas phase. The native state of $\mathrm{Ub}$ is a tightly-folded structure containing both $\alpha$-helix and $\beta$-sheet secondary structure 
elements (Supplemental Figure S1) [17-19]. This structure is very stable and is maintained over a wide range of $\mathrm{pH}$ values $(1.2 \sim 8.5)$ in aqueous solution [20-22]. However, acidic condition with organic co-solvent induces conformational changes, of which an example is helix-rich A-state formed with $60 \%$ methanol (by volume) at $\mathrm{pH} 2$ [21]. Loo et al. have further studied the effects of various organic solvents in acidic condition and have reported that $20 \%$ acetonitrile yields mainly the unfolded high charge $\mathrm{Ub}$ ions [22]. The gas phase $\mathrm{Ub}$ ions usually have charge distributions from +6 to +13 from an ESI source [5]. Charge states $+11,+12$, and +13 are usually from the denatured structures, and $+6,+7$, and +8 are from the native structure $[5,23]$. The correlations between charge state signatures and protein conformations have elicited active discussions in biophysics and mass spectrometry societies [24]. However, a number of studies have reported good correlation between Ub structures and charge states [5, 22-24].

Supramolecular chemistry, which examines weak intermolecular interactions, has been expanded to biological molecules [25]. Especially, well-defined host-guest systems between synthetic host molecules and proteins have been applied in various fields of applications such as protein folding and structure probing [26-30], protein immobilization and sensing [31-33], protein function control [34], and inhibition of abnormal protein self-assembly [35]. Although supramolecular synthesis of multicomponent architectures with various shapes and functions is possible in a wide range of applications, synthetic supramolecular applications with proteins are limited to small systems [25] and yet to be understood in detail at the molecular level. Cucurbit[6]uril (CB[6], Figure 1), a self-assembled neutral cyclic host molecule, is widely used in host-guest chemistry. The partially negative carbonyl-laced portals and hydrophobic interior allows specific recognition of Lys residues of proteins with moderately strong binding event in solution $\left(\mathrm{K}_{\mathrm{a}} \approx 10^{4} \mathrm{M}^{-1}\right)[36,37]$. Previously, we have reported that the large size (MW 996.8 Da) of $\mathrm{CB}[6]$ and its strong binding energy allow $\mathrm{CB}[6]$ to retain its binding to Lys residue of protein during the fragmentation processes in the gas phase by low energy collision-induced dissociation (CID) [37]. In addition, the doubly charged $\mathrm{CB}[6]$ complex of 5-iminopentylammonium (5IPA) is yielded from the formation of an internal imminium ion by multiple backbone dissociations. Then, potential utility of $\mathrm{CB}[6]$ to probe the surface structure of Ub has been demonstrated using ESI-MS. A mixture of $\mathrm{CB}[6]$ and $\mathrm{Ub}$ in water shows +7 to +14 charged $\mathrm{Ub}$ ion peaks with multiple $\mathrm{CB}[6]$ in the ESI-MS spectrum. With the analysis of +13 charged Ub-1CB[6] complex ion from water, we observed that $\mathrm{CB}[6]$ is bound to $\mathrm{Lys}_{6}$ or $\mathrm{Lys}_{11}$ of $\mathrm{Ub}$. On the other hand, an analysis of +13 charged Ub$\mathrm{CB}[6]$ complex ion from acidic organic solvent shows that $\mathrm{CB}[6]$ can bind to all Lys residues.

In this study, we investigate the $\mathrm{CB}[6]$ binding site of +7 charged complex ion. Then we compare the result with that of +13 charged complex ion. A crucial difference between two charge states are observed and show that $\mathrm{CB}[6]$ induces different conformations depending on different binding sites. Moreover, the CID analysis of double-CB[6] binding complex ions verifies the discussions. This gives us an understanding of conformational change of $\mathrm{Ub}$ and high charge state formation. The mechanism at the molecular level are explained and supported by combining ESI-MS ${ }^{n}$ with circular dichroism (CD) spectroscopy and molecular dynamics (MD) simulation. Then, controlling folding and unfolding of $\mathrm{Ub}$ is demonstrated using pentamethylenediamine (PMD) as a potential supramolecular switch system for controlling protein structures.

\section{Experimental}

\section{Chemicals and Reagents}

$\mathrm{Ub}, \mathrm{CB}[6]$, PMD, and formic acid were purchased from Sigma-Aldrich (St. Louis, MO, USA). All solvents (water and acetonitrile) were of HPLC grade and purchased from J. T. Baker (Phillipsburg, NJ, USA). CB[6] stock solution $(10 \mathrm{mM})$ was prepared by dissolving $\mathrm{CB}[6]$ in $80 \%$ formic acid. Sample solutions were prepared in two respective solvents consisting of water or 50/50 water/acetonitrile with $0.6 \%$ formic acid by volume (referred to as acidic acetonitrile in the paper). The final concentrations of $\mathrm{CB}[6]$ and $\mathrm{Ub}$ for ESI-MS and CD spectroscopy were adjusted to $70 \mu \mathrm{M}$ and $10 \mu \mathrm{M}$, respectively. $\mathrm{CB}[6]$ concentration was selected to be 7-fold of Ub concentration, as seven Lys residues are present in $\mathrm{Ub}$. The measured $\mathrm{pH}$ of the final $\mathrm{Ub}$ and $\mathrm{CB}[6]$ solution was 2.2 in water and 2.4 in acidic acetonitrile.
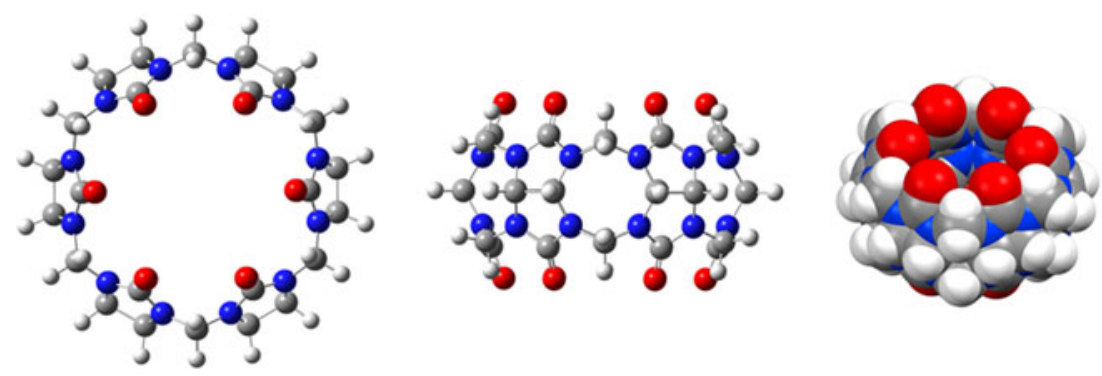

Figure 1. The top (left), side (middle) view, and space-filling structure (right) of cucurbit[6]uril 


\section{Electrospray Ionization Mass Spectrometry}

A Thermo Scientific LTQ Velos dual ion trap mass spectrometer equipped with normal ESI source was utilized in positive ion mode for the experiments. Electrospray voltage of $3.5 \mathrm{kV}$ and capillary temperature of $250{ }^{\circ} \mathrm{C}$ were set as parameters for ESI. Each spectrum was averaged from 100 scanned spectra obtained using enhanced scan mode for analysis. For the statistical analysis of mass and tandem mass spectra, at least seven spectra (each were averaged from 100 scanned spectra) obtained at different times were averaged. The nomenclature for the parent and fragment ions was adopted from Roepstorff and Fohlman [38]. The left asterisk (*) superscript for the $\mathrm{Ub}$ and fragment ion refers to the presence of $\mathrm{CB}[6]$ in the fragment. For example, a $y_{n}^{2+}$ fragment ion complex with $\mathrm{CB}[6]$ is referred to as $* y_{n}^{2+}$.

\section{Circular Dichroism Spectroscopy}

A Jasco J-815 spectropolarimeter equipped with peltier cell holder and $0.1 \mathrm{~cm}$ quartz cuvette was used to obtain CD spectra under constant nitrogen flow. All spectra are recorded in a wavelength interval of 190-260 nm, $0.1 \mathrm{~nm}$ data pitch by scanning at the rate of $20 \mathrm{~nm} /$ $\min$ at $20^{\circ} \mathrm{C}$. The spectra used in the present study were an average of three scans and smoothed using a FFT filter.

\section{Computational Modeling}

MD simulations were performed using the large scale atomic/molecular massively parallel simulator (LAMMPS) code [39]. The inter-atomic interactions were described by using the all-atom CHARMM PARAM27 force field (FF) [40], and the partial charge distribution of $\mathrm{CB}[6]$ was determined using Mulliken charge population analysis of the quantum mechanical (QM) wave function from density functional theory (DFT) calculation (B3LYP/6-31 G(d,p) using Gaussian 09) [41-43]. Table $\mathrm{S} 1$ shows the partial charge distribution of $\mathrm{CB}[6]$ from $\mathrm{QM}$ and $\mathrm{FF}$. We prepared four different complex structures of $\mathrm{Ub}$ and $\mathrm{CB}[6]$ depending on the interacting residue of $\mathrm{CB}[6]\left(\mathrm{Lys}_{6}, \mathrm{Lys}_{11}, \mathrm{Lys}_{48}\right.$, and $\left.\mathrm{Lys}_{63}\right)$. Ub structure was from PDB entry $1 \mathrm{D} 3 \mathrm{Z}$, which was charge-neutral with all lysine and arginine protonated, and all glutamic acid and aspartic acid deprotonated. Each of these was solvated with 81348159 water molecules. After the solvated complex was minimized, we elevated the simulation temperature from 0 to $300 \mathrm{~K}$ for $50 \mathrm{ps}$ to properly distribute the momentum to each atom. We then carried out 50 ps canonical ensemble MD simulations (NVT) to equilibrate the system at $300 \mathrm{~K}$, and then performed $\sim 10 \mathrm{~ns}$ isobaric-isothermal ensemble MD simulations (NPT). We note that a Nosé-Hoover thermostat and barostat were employed for the temperature and pressure control.

\section{Results and Discussion}

\section{ESI-MS of Ub with $C B[6]$}

Previously, we have reported that addition of $\mathrm{CB}[6]$ to $\mathrm{Ub}$ solution results in charge shift into high charge state [37]. The major charge states of $\mathrm{Ub}$ ions in aqueous solution range from +5 to +8 , and the ions are regarded as native-like structures. In acidic solution with high concentration of acetonitrile ( $50 \%$ by volume), an additional charge distribution ranging from +9 to +13 is observed [37]. These additional charge states are typically regarded as denatured structures $[5,23]$. When $\mathrm{CB}[6]$ is added to the solutions, dramatic changes occur. The abundance of low charge state ions are lowered and charge state distribution shifts into high charge state, inducing +12 and +13 charge state ions to be the most abundant.

To examine the phenomena quantitatively and confirm the relevance of charge shifts of Ub with $\mathrm{CB}[6]$, we have statistically investigated the relative abundances of $\mathrm{Ub}, \mathrm{Ub}-$ $1 \mathrm{CB}[6]$, and Ub-2CB[6] complexes of each charge state. It is found that in water, the relative abundance of the uncomplexed $\mathrm{Ub}$ ion in high charge states is significantly low (Figure 2a). On the other hand, in the +7 charge state, the relative abundance of $\mathrm{Ub}$ ion without $\mathrm{CB}[6]$ is the greatest. This shows that in water, denatured high charge state is formed by host-guest interaction of $\mathrm{CB}[6]$ with $\mathrm{Ub}$. A
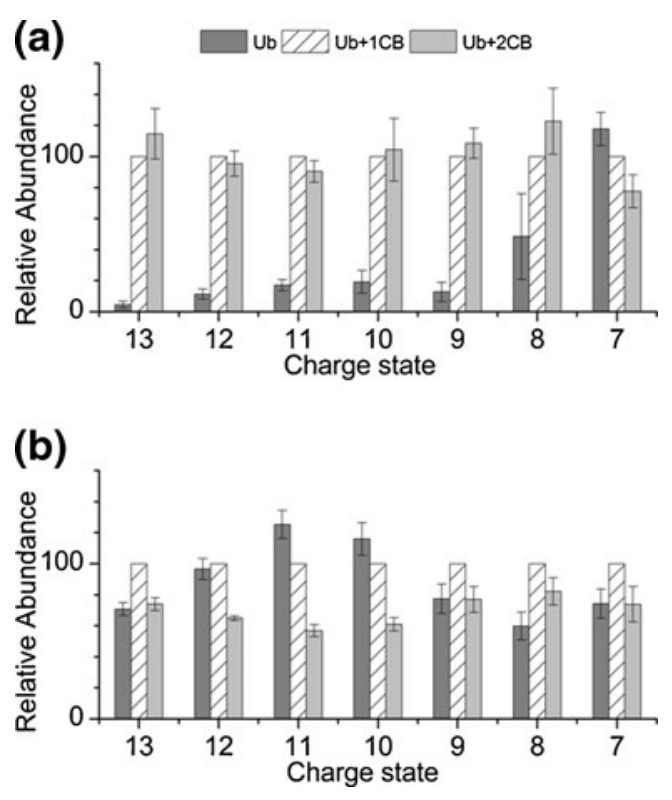

Figure 2. Relative abundances of $\mathrm{Ub}, \mathrm{Ub}+1 \mathrm{CB}, \mathrm{Ub}+2 \mathrm{CB}$ ions with +7 to +13 charge states from (a) water and from (b) acidic acetonitrile. The relative abundance of $U b+1 C B$ is arbitrarily assigned to be hundred. Data from seven independent spectra were averaged 
difference is observed with a denaturing condition of acidic acetonitrile (Figure 2b). In this condition, the relative abundance of uncomplexed $\mathrm{Ub}$ ion in high charge states is comparable, or even exceeds the abundances of complexed ions. The result is in accordance with the denaturing solvent condition, which provides a distinct pathway of Ub denaturation. As formation of high charge state is possible by solvent-induced denaturation, the existence of high charge state ions without $\mathrm{CB}[6]$ is not only possible, but is also very probable, as the data suggest.

\section{Circular Dichroism Studies of Ub-CB[6] Complex in the Solution Phase}

In order to confirm the correlation between the observed charge distribution changes in the ESI-MS spectra and structural changes of $\mathrm{Ub}$ in the solution phase by addition of $\mathrm{CB}[6], \mathrm{CD}$ spectroscopy is used to examine the secondary structures of $\mathrm{Ub}$ in the solution phase. Characteristic CD ellipticity for each secondary structural component ( $\alpha$-helix, $\beta$-sheet, and random structures) is listed in Supplemental Table S2. The CD spectrum of $\mathrm{Ub}$ in water shows a good agreement with the previously reported CD spectrum of the native state Ub (Supplemental Figure S2a), which comprises a mixed structure of $\alpha$-helix (positive ellipticity at $190 \mathrm{~nm}$ and negative ellipticity at 208 and $222 \mathrm{~nm}$ ) and $\beta$-sheet (negative ellipticity at $215 \mathrm{~nm}$ ) elements [19]. The CD spectrum of $\mathrm{Ub}$ in water with formic acid shows that the portion of random structure slightly increases (Supplemental Figure S2a). Addition of $\mathrm{CB}[6]$ exhibits significant increase of random structure of the protein (Supplemental Figure S2a). This indicates that the complexation with $\mathrm{CB}[6]$ via host-guest interaction induces major conformational change of $\mathrm{Ub}$ from its native state to a denatured state in the solution phase. This supports that the observed shift in the charge states upon addition of $\mathrm{CB}[6]$ in ESI-MS spectra is caused by the conformational change of $\mathrm{Ub}$ following the complexation.

The $\mathrm{CD}$ spectrum of $\mathrm{Ub}$ and its mixture with $\mathrm{CB}[6]$ in acidic acetonitrile shows a clear difference compared with the structural change of $\mathrm{Ub}$ in water (Supplemental Figure S2b). The helical secondary structure component of $\mathrm{Ub}$ increases due to denaturation following the addition of acid to water/acetonitrile. The $\mathrm{CD}$ spectrum of $\mathrm{Ub}$ in acidic acetonitrile shows high similarity to the previously reported $\mathrm{CD}$ spectrum of the A-state structure of Ub [44]. No significant secondary structure change is observed by addition of $\mathrm{CB}[6]$. This is due to the relatively weak correlation between the denaturation of $\mathrm{Ub}$ and $\mathrm{CB}[6]$ complexation in acidic acetonitrile. The denatured conformation is already formed by the solvent effect. Therefore, the role of $\mathrm{CB}[6]$ in acidic acetonitrile is limited to the conformation change of the native-like structured $\mathrm{Ub}$. Thus the conformational change induced by $\mathrm{CB}[6]$ is minor so that the $\mathrm{CD}$ spectrum does not show much difference.

\section{ESI-MS ${ }^{2}$ of Ub-1CB[6] Complex Ions}

It is interesting that in both solvent conditions, $\mathrm{CB}[6]$ binding does not necessarily induce high charge state formation. +7 charge state ions with $\mathrm{CB}[6]$ are present in significant quantity. In other words, some conformations with $\mathrm{CB}[6]$ lead to the denaturation of $\mathrm{Ub}$, whereas some do not. We hypothesized that different binding site of $\mathrm{CB}[6]$ in Ub may be the cause. Our previous study shows that $\mathrm{CB}[6]$ binding site could be deduced with CID and that $\mathrm{CB}[6]$ is bound to $\mathrm{Lys}_{6}$ or $\mathrm{Lys}_{11}$ for +13 charge state ions from water, and to any Lys for +13 charge state ions from acidic acetonitrile [37].

In the present study, we have carried out multiple CID investigation of +7 charged Ub-1CB[6] complex ions both from water and acidic acetonitrile. A recent study by Oldham and co-workers discusses the relationship between the stability of noncovalent interactions between Ub-modified substrates and Ub-binding domains along with their charge states [45]. The study has reported that highly charged complex ion has higher tendency to lose its noncovalent interactions because of the repulsion between charged binding partners and relatively high kinetic energy gained during ESI process [45]. However, this is not applicable to our case as CB[6]-Lys interaction is an iondipole interaction, and also is strong enough to be retained during CID processes [37].

CID spectra of +7 charged $\mathrm{Ub}$ with a single $\mathrm{CB}[6]$ from both water and acidic acetonitrile show identical fragments (Supplemental Figures S3a and S3b). Both spectra show that $\mathrm{CB}[6]$ prefers to bind to $\mathrm{y}_{58-63}$ fragments, and $\mathrm{MS}^{3}$ analysis reveals that $\mathrm{CB}[6]$ is found at $\mathrm{Lys}_{48}$ and $\mathrm{Lys}_{63}$ (Supplemental Figures S3c and S3d). As discussed earlier, +7 charge state of $\mathrm{Ub}$ represents its native folding state in the solution

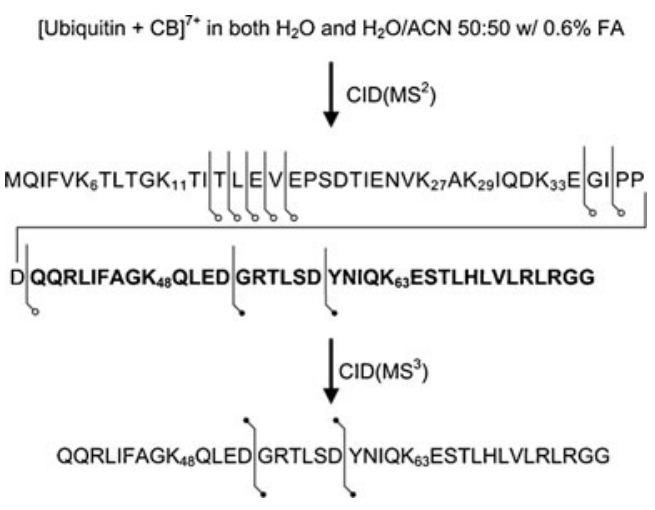

Scheme 1. Dissociation pathways of +7 charged Ub-1CB[6] complexes from both water and acidic acetonitrile. Both solvent condition exhibit identical dissociation pathways. Indicated products are further probed by $\mathrm{MS}^{3}$. Observation of only fragment-CB[6] complexes in $\mathrm{MS}^{\mathrm{n}}$ spectra is denoted as an empty circle. Solid circle denotes the presence of both fragments and fragment-CB[6] complexes 

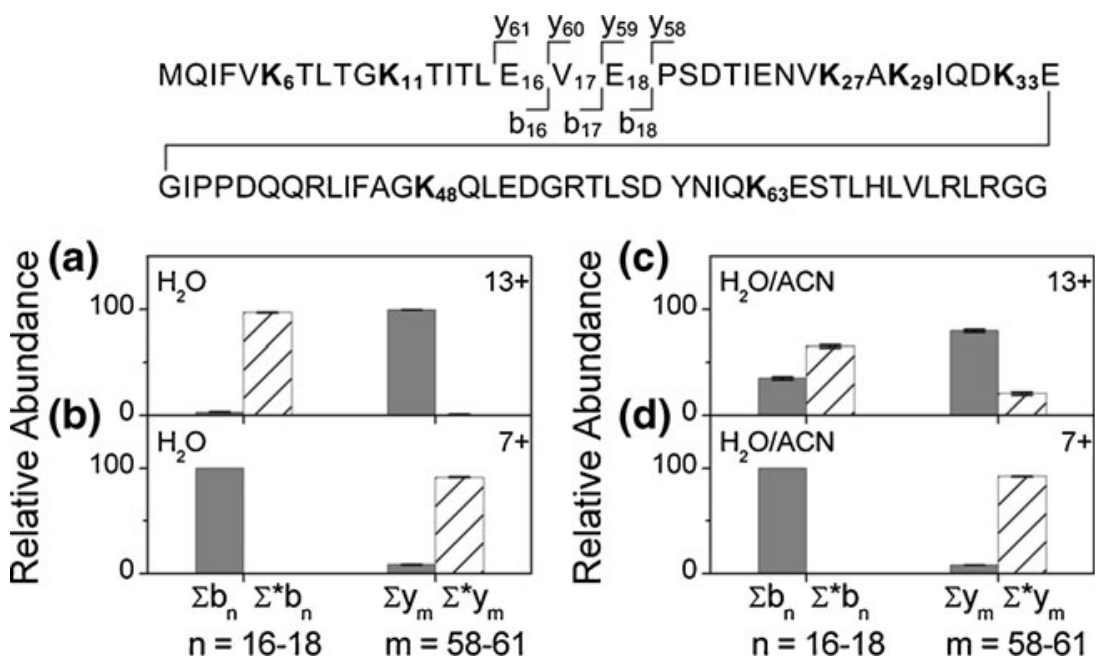

Figure 3. Relative abundances of $b_{16}, b_{17}, b_{18}$ fragments with and without $C B[6]$, and $y_{58}, y_{59}, y_{60}, y_{61}$ fragments with and without $\mathrm{CB}[6]$, in the CID spectra of Ub-1CB[6] complex ions with +13 charge state (a) from water and (b) from acidic acetonitrile, and with +7 charge state (c) from water and (d) from acidic acetonitrile. The Lys ${ }_{6}$ and Lys L $_{11}$ are included in b-

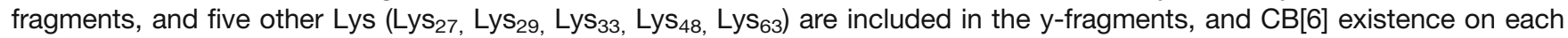
fragment means $\mathrm{CB}[6]$ binding to the respective Lys. The gray and slashed bars represent the relative abundance of fragments without and with $\mathrm{CB}[6]$, respectively. Data from six independent spectra were averaged

phase $[5,23]$. Thus, the observed charge state and binding location of $\mathrm{CB}[6]$ indicate that no significant change in conformation of $\mathrm{Ub}$ occurs with the attachment of $\mathrm{CB}[6]$ to Lys $_{48}$ and Lys 63 residues. The CID processes of +7 charged $\mathrm{Ub}-1 \mathrm{CB}[6]$ complex ions are summarized in Scheme 1.

The relative abundances between CID fragments of $\mathrm{Ub}$ with and without $\mathrm{CB}[6]$ provide strong correlation between charge state of $\mathrm{Ub}$ and $\mathrm{CB}[6]$ binding sites (Figure 3). The abundances of the sum of $b_{16}, b_{17}, b_{18}$ fragments are compared with the abundances of corresponding $\mathrm{CB}[6]$ complex fragments $\left(* \mathrm{~b}_{16}, * \mathrm{~b}_{17}\right.$, $\left.* b_{18}\right)$. The relative abundances of the sum of $\mathrm{y}_{58}, \mathrm{y}_{59}$, $\mathrm{y}_{60}, \mathrm{y}_{61}$, and the corresponding $\mathrm{CB}[6]$ complex fragments $\left({ }^{*} \mathrm{y}_{58},{ }^{*} \mathrm{y}_{59},{ }^{*} \mathrm{y}_{60}, *^{*} \mathrm{y}_{61}\right)$ are also compared. Figure $3 \mathrm{a}$ shows that the +13 charged $\mathrm{Ub}-1 \mathrm{CB}[6]$ ion from water has its interacting $\mathrm{CB}[6]$ exceptionally at $\mathrm{b}$ fragments: complexation at $\mathrm{Lys}_{6}$ or $\mathrm{Lys}_{11}$. In contrast, +7 charged $\mathrm{Ub}-1 \mathrm{CB}[6]$ ion has its interacting $\mathrm{CB}[6]$ exceptionally at y fragments: complexation at $\mathrm{Lys}_{27}, \mathrm{Lys}_{29}, \mathrm{Lys}_{33}, \mathrm{Lys}_{48}$, or $\mathrm{Lys}_{63}$ (Figure 3b). Further CID $\left(\mathrm{MS}^{3}\right)$ investigation reveals the binding sites to be $\mathrm{Lys}_{48}$ and $\mathrm{Lys}_{63}$. Thus, it can be concluded that a binding of $\mathrm{CB}[6]$ to $\mathrm{Lys}_{48}$ and Lys $_{63}$ does not induce denaturation, whereas a binding of $\mathrm{CB}[6]$ to $\mathrm{Lys}_{6}$ or $\mathrm{Lys}_{11}$ induces denaturation.
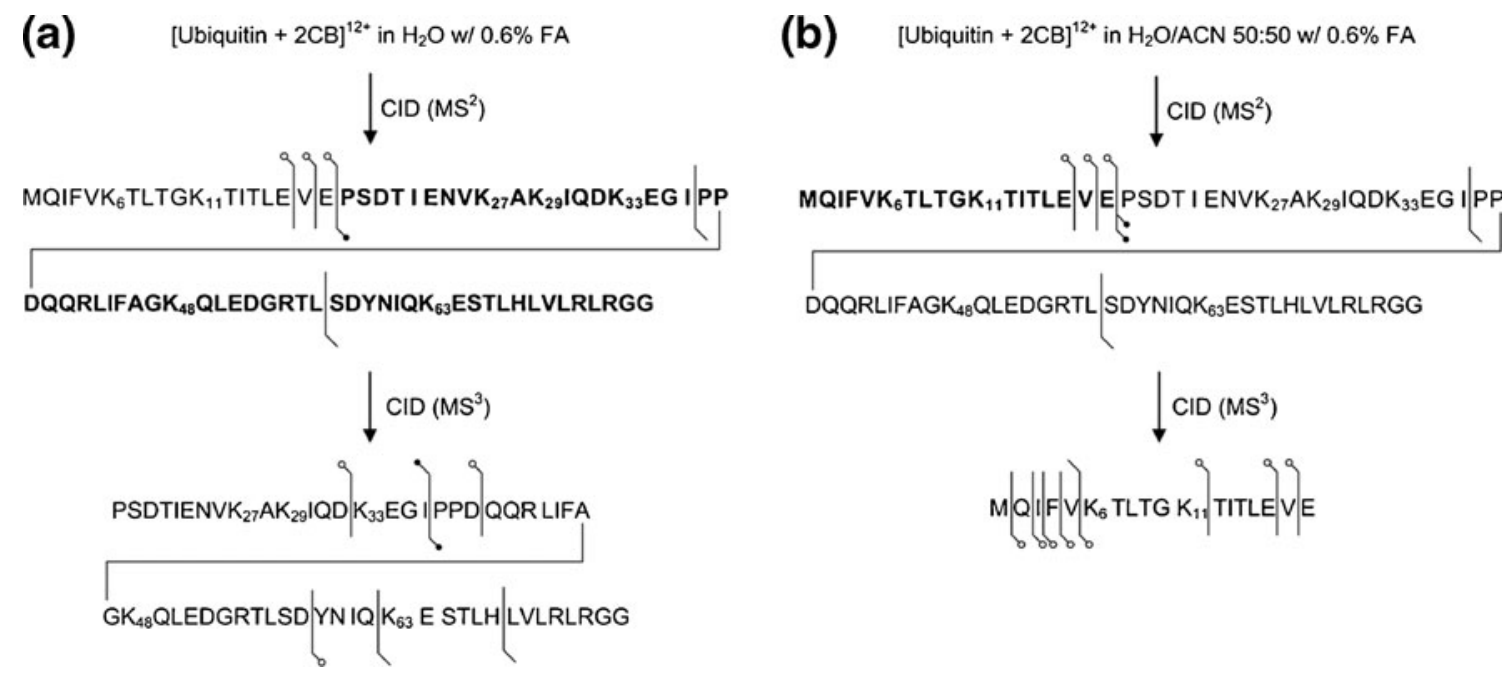

Scheme 2. Dissociation pathways of +12 charged ubiquitin with two CB[6] (a) from water and (b) from acidic acetonitrile inferred from CID. Indicated products with two $\mathrm{CB}[6]$ are further probed by $\mathrm{MS}^{3}$. Observation of only fragment-CB[6] complexes in $\mathrm{MS}^{\mathrm{n}}$ spectra is denoted as an empty circle. Solid circle denotes the presence of both fragments and fragment-CB[6] complexes 
(a)

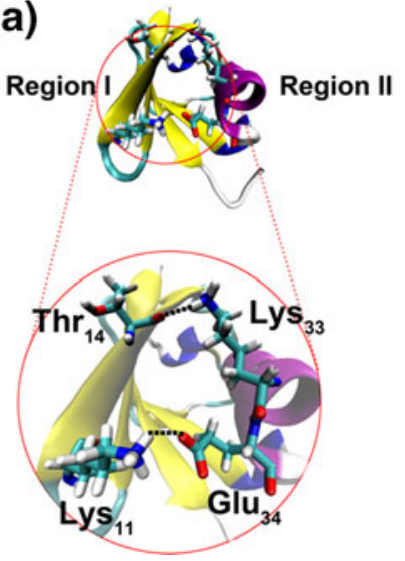

Figure 4. (a) Native structure of Ub (PDB entry 1D3Z). (b) Final snapshot after 10.0 ns of MD simulations of $\mathrm{Ub}$ complex of $\mathrm{CB}[6]$ to Lys $_{11}$

The +13 charged Ub-1CB[6] ion from acidic acetonitrile shows a different fragmentation pattern (Figure $3 \mathrm{c}$ ). Both $\mathrm{b}$ fragments $\left(b_{16}, b_{17}, b_{18}\right)$ and $y$ fragments $\left(y_{58}, y_{59}, y_{60}, y_{61}\right)$ with $\mathrm{CB}[6]$ are observed. $\mathrm{MS}^{3}$ investigation shows that $\mathrm{CB}[6]$ binding occurs at even $\mathrm{Lys}_{27}$, $\mathrm{Lys}_{29}$, and $\mathrm{Lys}_{33}$, which are buried inside of the protein when it is in the native state The denaturing solvent condition leads to the exposure of inner Lys and allows $\mathrm{CB}[6]$ to bind. Figure $3 \mathrm{~d}$, the CID data of +7 charged $\mathrm{Ub}-1 \mathrm{CB}[6]$ ion from acidic acetonitrile, is almost identical to that of the ion from water. This further confirms that binding $\mathrm{CB}[6]$ to $\mathrm{Lys}_{48}$ and $\mathrm{Lys}_{63}$ preserves the native state of $\mathrm{Ub}$ and retains its low charge state.

\section{ESI-MS ${ }^{2}$ of Ub-2CB[6] Complex Ions}

To verify the observed correlation between the complexation of $\mathrm{Ub}$ with $\mathrm{CB}[6]$ and its structure, the CID analysis of $\mathrm{Ub}$

(b)

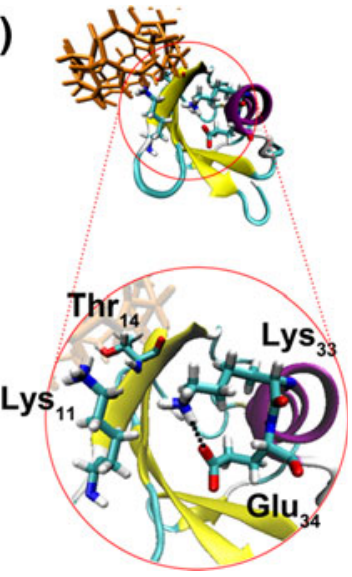

complex ions with two $\mathrm{CB}[6]$ (Ub-2CB[6]) is further performed. The CID of the +12 charged Ub-2CB[6] complex ion from water yields $* \mathrm{y}_{58},{ }^{*} \mathrm{~b}_{17}$, and $* \mathrm{~b}_{18}$ fragments (Supplemental Figure S4a). This indicates that a $\mathrm{CB}[6]$ is attached at $\mathrm{Lys}_{6}$ or $\mathrm{Lys}_{11}$ and the other CB[6] is attached to any one of other Lys residues from 27 to 63 . We infer that once the protein structure is changed to the unfolded structure by complexation of $\mathrm{CB}[6]$ to $\mathrm{Lys}_{6}$ or Lys $_{11}$, all the rest of Lys residues are accessible to CB[6].

Distinct CB[6] binding sites are observed from the CID of Ub-2CB[6] complex ions from acidic acetonitrile (Supplemental Figure S4b). The CID analysis of +12 charged Ub-2CB[6] complex ion additionally yields $* * \mathrm{y}_{58}$, whose two $\mathrm{CB}[6]$ interact with two Lys residues from 27 to 63 . Since the protein is already at a denatured state, of which all Lys residues are exposed outside, two $\mathrm{CB}[6]$ can bind to any two Lys residues from 27 to 63 . In this case, binding of $\mathrm{CB}[6]$ to $\mathrm{Lys}_{6}$ or $\mathrm{Lys}_{11}$ residue is not a necessity for highly charged complex formation from acidic acetonitrile. The CID processes of +12 charged Ub-2CB[6] complex ions are summarized in Scheme 2.

\section{Conformational Changes of Ub by Host-Guest Chemistry with $C B[6]$}

The present study demonstrates that binding of $\mathrm{CB}[6]$ to Lys $_{6}$ or Lys Lyd $_{11}$ induces conformational change of Ub in water differently from the change induced by organic solvent. MD simulations provide further insight into structural changes of Ub by complexation with $\mathrm{CB}[6]$ in an aqueous environment. We use the all-atom CHARMM PARAM27 force field and TIP3P potential to mimic a water environment [40]. These simulations exhibit no critical changes in intramolecular interactions of $\mathrm{Ub}$ by complexation of $\mathrm{Lys}_{48}$ and $\mathrm{Lys}_{63}$ with

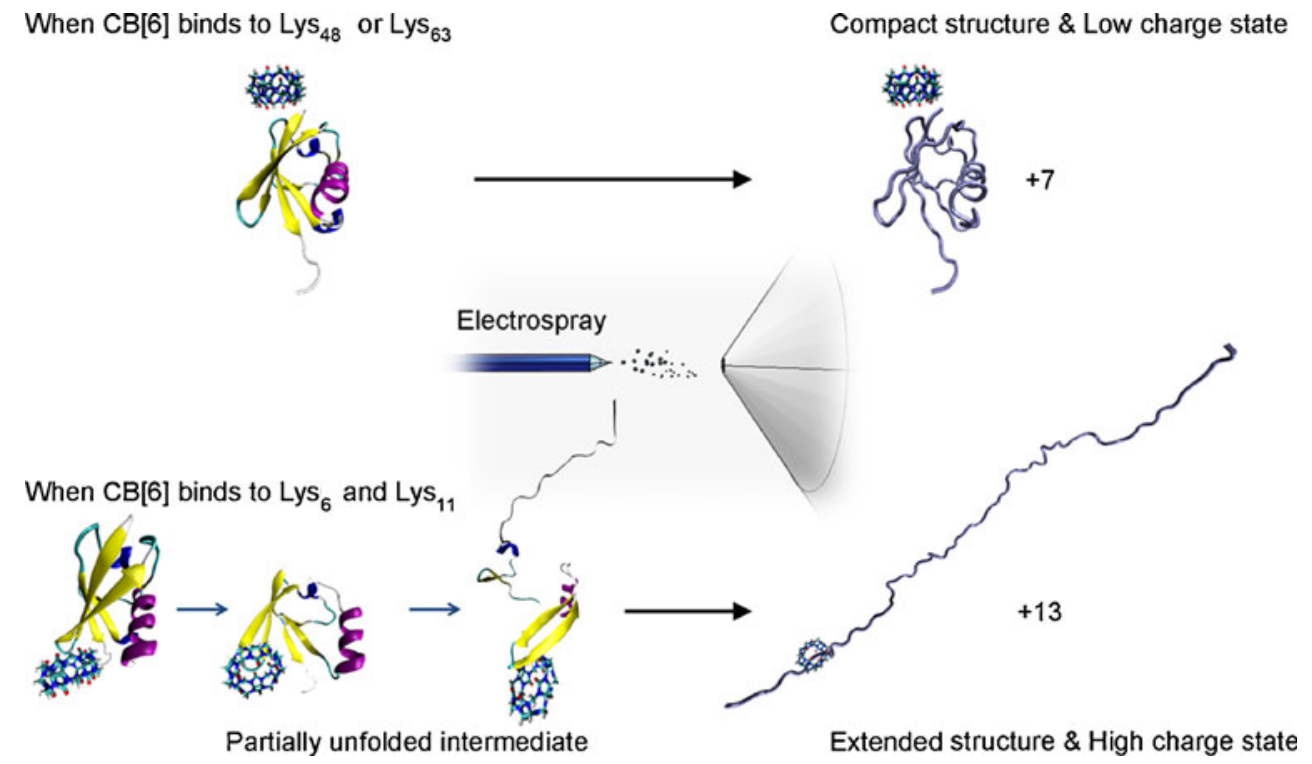

Figure 5. Proposed mechanistic diagrams for structural changes and charge states of Ub by host-guest chemistry with CB[6]. The figure is for illustrative purposes only 
a CB[6] (Supplemental Figures S5a and S5b, respectively), which is consistent with experimental observation. Significant changes in intramolecular interactions of $\mathrm{Ub}$ are observed when $\mathrm{CB}[6]$ is attached to Lys ${ }_{11}$. The host-guest interaction between $\mathrm{CB}[6]$ and $\mathrm{Lys}_{11}$ prohibits $\mathrm{Lys}_{11}$ from forming a salt bridge with $\mathrm{Glu}_{34}$, which links between $\beta$ sheet in region I (residues 1-18) and $\alpha$-helix in region II (residues 19-35, Figure 4a). As a result, an intra-regional salt bridge is formed between $\mathrm{Glu}_{34}$ and $\mathrm{Lys}_{33}$, while an inter-regional $\mathrm{H}$-bond between $\mathrm{Lys}_{33}$ and $\mathrm{Thr}_{14}$ is broken (Figure 4b). Two important inter-regional interactions between region I and region II are broken by host-guest interaction between $\mathrm{Lys}_{11}$ and $\mathrm{CB}[6]$. This results in loosening of the tightly folded structure of $\mathrm{Ub}$, and eventually induces the conformational change of $\mathrm{Ub}$ in water. This theoretical investigation supports the experimental observations that conformational change of Ub occurs by specific host-guest interaction between $\mathrm{Lys}_{11}$ and $\mathrm{CB}[6]$ in the solution phase. No significant change in inter-regional interaction is observed when $\mathrm{CB}[6]$ is attached to $\mathrm{Lys}_{6}$ (Supplemental Figure S5c). We infer that CB[6], which binds to Lys $_{11}$, interacts with adjacent Lys $_{6}$ [46] simultaneously during the conformational changes of $\mathrm{Ub}$ to induce further changes in protein conformation.

The interaction between Lys residues and $\mathrm{CB}[6]$ is known to be moderately strong $\left(\mathrm{K}_{\mathrm{a}} \cong 10^{4} \mathrm{M}^{-1}\right)$ in the solution phase [36], so the specific interaction of $\mathrm{CB}[6]$ is expected to be limited to Lys residues which do not have strong salt bridge interactions. Thus, it is hard to expect that $\mathrm{CB}[6]$ alone can defy the salt bridge between $\mathrm{Lys}_{11}$ and $\mathrm{Glu}_{34}$ and induce conformational change of $\mathrm{Ub}$. The mixture solution of $10 \mu \mathrm{M} \mathrm{Ub}$ and $70 \mu \mathrm{M}$ $\mathrm{CB}[6]$ contains approximately $0.6 \%$ of formic acid since $\mathrm{CB}[6]$ is dissolved in acidic solution [47, 48]. The native structure of $\mathrm{Ub}$ is very stable and is maintained upon addition of acid in aqueous solution [20,21]. We have tested ESI-MS of $\mathrm{Ub}$ in water with $0.6 \%$ formic acid to understand the effect of the acid alone to the charge distribution in the MS spectrum. The ESI-MS spectrum of $\mathrm{Ub}$ from water with formic acid (Supplemental Figure S6a) shows very similar charge distribution of $\mathrm{Ub}$ from water without formic acid (Supplemental Figure S6b). This indicates that the native structure of $\mathrm{Ub}$ is not directly influenced by acidic solution condition. We infer that the acidic condition of the solution may weaken the salt bridge between $\mathrm{Lys}_{11}$ and $\mathrm{Glu}_{34}$ to allow $\mathrm{CB}[6]$ to bind to $\mathrm{Lys}_{11}$. Once the salt bridge is weakened by acidic condition, the attachment of $\mathrm{CB}[6]$ to $\mathrm{Lys}_{11}$ is considered to induce further denaturation of Ub. Additional expansion of Ub structure would be expected in the charged droplet from ESI which results in the observed charge shift in the ESI-MS spectrum (Figure 5). Previous study of structures of Ub using selective noncovalent adduct protein probing (SNAPP) by Julian and co-workers has reported weak salt bridge between $\mathrm{Lys}_{11}$ and $\mathrm{Glu}_{34}$ along with dynamic structural motions of the protein involved with $\mathrm{Lys}_{11}$ [27]. A recent report by Breuker and co-workers has also addressed the importance of salt bridges in stabilizing gas phase structures [49].

\section{Controlling Ub Conformations by Host-Guest Chemistry of $C B[6]$ with PMD}

The observed conformational changes of $\mathrm{Ub}$ is primarily induced by moderately strong $\left(\mathrm{K}_{\mathrm{a}} \cong 10^{4} \mathrm{M}^{-1}\right)$ interactions between $\mathrm{CB}[6]$ and $\mathrm{Lys}_{11}$ in the solution phase [36]. CB[6] exhibits strong binding properties to $\alpha, \omega$-alkyldiammonium cations with alkyl chain, which comprises four to six carbons [50]. Refolding to the native state of the $\mathrm{Ub}$ unfolded by $\mathrm{CB}[6]$ beforehand, is examined using pentamethylenediamine (PMD, Supplemental Figure S7) as a potential supramolecular switch for controlling protein structures. PMD binds to $\mathrm{CB}[6]$ strongly $\left(\mathrm{K}_{\mathrm{a}} \geq 10^{5} \mathrm{M}^{-1}\right)$ in

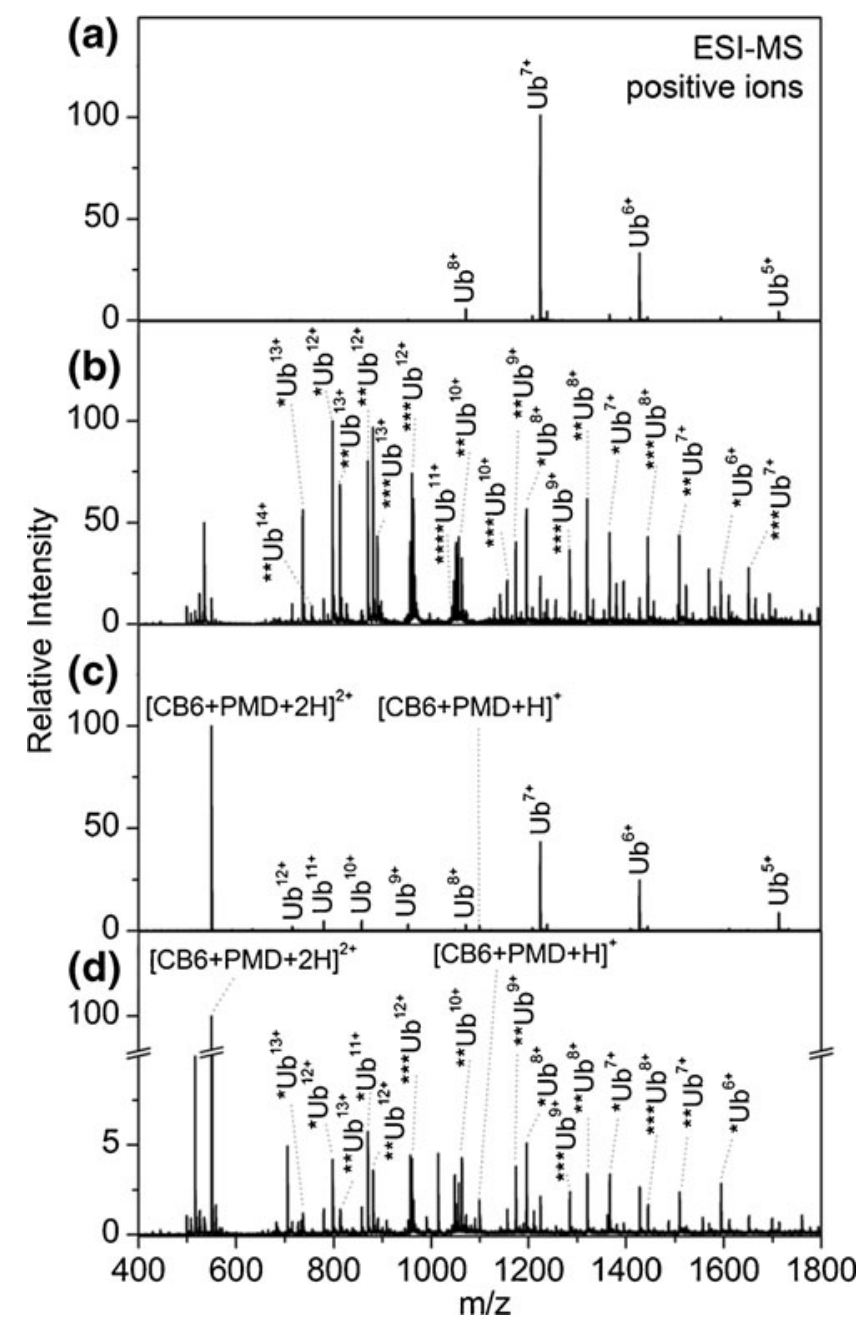

Figure 6. ESI-MS spectra of (a) $\mathrm{Ub}(10 \mu \mathrm{M})$, (b) $\mathrm{Ub}(10 \mu \mathrm{M})$ with $\mathrm{CB}[6](70 \mu \mathrm{M})$, (c) a mixture of $\mathrm{Ub}(10 \mu \mathrm{M})$ and $\mathrm{CB}[6]$ $(70 \mu \mathrm{M})$ followed by an addition of PMD $(70 \mu \mathrm{M})$, and (d) a mixture of $\mathrm{Ub}(10 \mu \mathrm{M}), \mathrm{CB}[6](70 \mu \mathrm{M})$, and PMD $(70 \mu \mathrm{M})$ followed by an addition of $\mathrm{CB}[6](70 \mu \mathrm{M})$ from water 
the solution because of its suitable alkyl chain length $(\sim 8 \AA)$ to the cavity depth $(\sim 9 \AA)$ and two ammonium groups, which interact with two carbonyl-laced portals [50].

ESI-MS spectrum of Ub in water shows a dominating charge distribution in the range of +5 to +8 , which represents the native structure of $\mathrm{Ub}$ in the solution phase (Figure 6a) $[5,23]$. The complexations and conformational changes of $\mathrm{Ub}(10 \mathrm{uM})$ by $\mathrm{CB}[6](70 \mu \mathrm{M})$ is confirmed by ESI-MS (Figure 6b). The ESI-MS of a mixture of Ub and $\mathrm{CB}[6]$ from water shows a significant shift in charge states of Ub up to +14 with multiple (up to four) $\mathrm{CB}[6]$ attachments as reported from our previous study [37]. Then, $70 \mu \mathrm{M}$ PMD is added to a mixture of $\mathrm{Ub}$ and $\mathrm{CB}[6](10 \mu \mathrm{M}$ and $70 \mu \mathrm{M}$, respectively) in water to refold $\mathrm{Ub}$ to its native state. The ESI-MS spectrum of a mixture of $\mathrm{Ub}$ and $\mathrm{CB}[6]$, after the addition of PMD, shows major peak at $\mathrm{m} / \mathrm{z} 550.2$, which corresponds to doubly charged CB[6]-PMD complex ion (Figure 6c). The addition of PMD to the Ub-CB[6] mixture detaches $\mathrm{CB}[6]$ from $\mathrm{Ub}$ by forming $\mathrm{CB}[6]-\mathrm{PMD}$ complex in the solution. Ub ions exhibit a major charge distribution in the range of +5 to +8 , which represents the native structure of $\mathrm{Ub}$ in the solution phase. A minor charge distribution in the range of +9 to +13 is additionally observed from the spectrum. This minor charge distribution results from a relatively low abundance of permanently denatured $\mathrm{Ub}$ that has been formed by host-guest interactions with $\mathrm{CB}[6]$. No significant $\mathrm{Ub}-\mathrm{CB}[6]$ complex ion is observed in the spectrum. Finally, $70 \mu \mathrm{M}$ of $\mathrm{CB}[6]$ is, again, added to the solution which formerly comprises $10 \mu \mathrm{M} \mathrm{Ub}$, $70 \mu \mathrm{M} \mathrm{CB}[6]$, and $70 \mu \mathrm{M}$ PMD. Addition of extra amount $(70 \mu \mathrm{M})$ of $\mathrm{CB}[6]$ to the final solution, again, results in charge shift, and hence, conformational changes of $\mathrm{Ub}$ (Figure 6d).

\section{Conclusions}

We have probed distinct conformational change mechanisms and dynamics of $\mathrm{Ub}$ by host-guest chemistry with $\mathrm{CB}[6]$ at the molecular level compared with solvent driven conformational change using ESI-MS combined with CD spectroscopy and MD simulations. Under acidic condition, $\mathrm{CB}[6]$ causes dramatic conformational change of the protein and this results in shifts in major charge states up to +14 with multiple $\mathrm{CB}[6]$ attachments in the ESI-MS spectrum. Tandem MS analysis indicates that binding of CB[6] to Lys 6 and $\mathrm{Lys}_{11}$ causes conformational change of the protein. Then, controlling folding and unfolding of $\mathrm{Ub}$ is demonstrated by addition of a series of stoichiometric amount of $\mathrm{CB}[6]$ an PMD by attaching and detaching $\mathrm{CB}[6]$ from Ub. Our study provides mechanistic details about the conformational changes of $\mathrm{Ub}$ by host-guest interactions with $\mathrm{CB}[6]$. Small residual changes by host-guest interactions can induce dramatic structural change of the protein, which is an important factor for designing building blocks for biologically functional supramolecular architectures using proteins and synthetic host molecules. Understanding supramolecular interactions of the system in detail at the molecular level provides us a direction to control protein structures, which is directly related to controlling protein functionality.

\section{Acknowledgments}

The authors acknowledge support for this work by Basic Science Research (grant no. 2010-0021508) through the National Research Foundation (NRF) of Korea funded by the Ministry of Education, Science, and Technology (MOEST).

\section{References}

1. Schuler, B., Eaton, W.A.: Protein folding studied by single-molecule FRET. Curr. Opin. Struct. Biol. 18(1), 16-26 (2008)

2. Fu, L., Liu, J., Yan, E.C.Y.: Chiral sum frequency generation spectroscopy for characterizing protein secondary structures at interfaces. J. Am. Chem. Soc. 133(21), 8094-8097 (2011)

3. Liu, G., Prabhakar, A., Aucoin, D., Simon, M., Sparks, S., Robbins, K.J., Sheen, A., Petty, S.A., Lazo, N.D.: Mechanistic studies of peptide self-assembly: Transient $\alpha$-helices to stable $\beta$-sheets. J. Am. Chem. Soc. 132(51), 18223-18232 (2010)

4. Breuker, K., McLafferty, F.W.: Stepwise evolution of protein native structure with electrospray into the gas phase, $10(-12)$ to $10(2)$ S. Proc. Natl. Acad. Sci. U. S. A. 105(47), 18145-18152 (2008)

5. Wyttenbach, T., Bowers, M.T.: Structural stability from solution to the gas phase: Native solution structure of ubiquitin survives analysis in a solvent-free ion mobility-mass spectrometry environment. J. Phys. Chem. B 115(42), 12266-12275 (2011)

6. Hoaglund-Hyzer, C.S., Counterman, A.E., Clemmer, D.E.: Anhydrous protein ions. Chem. Rev. 99(10), 3037-3079 (1999)

7. Jenner, M., Ellis, J., Huang, W.C., Raven, E.L., Roberts, G.C.K., Oldham, N.J.: Detection of a protein conformational equilibrium by electrospray ionisation-ion mobility-mass spectrometry. Angew. Chem. Int. Ed. 50(36), 8291-8294 (2011)

8. Liu, L., Bagal, D., Kitova, E.N., Schnier, P.D., Klassen, J.S.: Hydrophobic protein-ligand interactions preserved in the gas phase. $J$. Am. Chem. Soc. 131(44), 15980-15981 (2009)

9. Pierson, N.A., Chen, L.X., Valentine, S.J., Russell, D.H., Clemmer, D.E.: Number of solution states of bradykinin from ion mobility and mass spectrometry measurements. J. Am. Chem. Soc. 133(35), 1381013813 (2011)

10. Ruotolo, B.T., Giles, K., Campuzano, I., Sandercock, A.M., Bateman, R.H., Robinson, C.V.: Evidence for macromolecular protein rings in the absence of bulk water. Science 310(5754), 1658-1661 (2005)

11. Pickart, C.M.: Mechanisms underlying ubiquitination. Annu. Rev. Biochem. 70, 503-533 (2001)

12. Hershko, A., Ciechanover, A.: The ubiquitin system. Annu. Rev. Biochem. 67, 425-479 (1998)

13. Pickart, C.M.: Ubiquitin in chains. Trends Biochem. Sci. 25(11), 544-548 (2000)

14. Hershko, A., Ciechanover, A., Varshavsky, A.: The ubiquitin system. Nat. Med. 6(10), 1073-1081 (2000)

15. Komander, D.: The emerging complexity of protein ubiquitination. Biochem. Soc. Trans. 37, 937-953 (2009)

16. Pickart, C.M., Fushman, D.: Polyubiquitin chains: Polymeric protein signals. Curr. Opin. Chem. Biol. 8(6), 610-616 (2004)

17. Di Stefano, D.L., Wand, A.J.: Two-dimensional proton NMR study of human ubiquitin: a main chain directed assignment and structure analysis. Biochemistry 26(23), 7272-7281 (1987)

18. Vijay-kumar, S., Bugg, C.E., Cook, W.J.: Structure of ubiquitin refined at 1.8 Å resolution. J. Mol. Biol. 194(3), 531-544 (1987)

19. Love, S.G., Muir, T.W., Ramage, R., Shaw, K.T., Alexeev, D., Sawyer, L., Kelly, S.M., Price, N.C., Arnold, J.E., Mee, M.P., Mayer, R.J.: Synthetic, structural and biological studies of the ubiquitin system: Synthesis and crystal structure of an analogue containing unnatural amino acids. Biochem. J. 323, 727-734 (1997)

20. Lenkinski, R.E., Chen, D.M., Glickson, J.D., Goldstein, G.: Nuclear magnetic resonance studies of the denaturation of ubiquitin. Biochim. Biophys. Acta. 494, 126-130 (1977) 
21. Harding, M.M., Williams, D.H., Woolfson, D.N.: Characterization of a partially denatured state of a protein by two-dimensional NMR: reduction of the hydrophobic interactions in ubiquitin. Biochemistry 30(12), 572 3120-3128 (1991)

22. Loo, J.A., Loo, R.R.O., Udseth, H.R., Edmonds, C.G., Smith, R.D.: Solvent-induced conformational changes of polypeptides probed by electrospray-ionization mass spectrometry. Rapid Commun. Mass Spectrom. 5(3), 101-105 (1991)

23. Li, J.W., Taraszka, J.A., Counterman, A.E., Clemmer, D.E.: Influence of solvent composition and capillary temperature on the conformations of electrosprayed ions: Unfolding of compact ubiquitin conformers from pseudonative and denatured solutions. Int. J. Mass Spectrom. 185, 37-47 (1999)

24. Hall, Z., Robinson, C.V.: Do charge state signatures guarantee protein conformations? J. Am. Soc. Mass Spectrom. 23(7), 1161-1168 (2012)

25. Uhlenheuer, D.A., Petkau, K., Brunsveld, L.: Combining supramolecular chemistry with biology. Chem. Soc. Rev. 39(8), 2817-2826 (2010)

26. Ly, T., Julian, R.R.: Using ESI-MS to probe protein structure by sitespecific noncovalent attachment of 18-crown-6. J. Am. Soc. Mass Spectrom. 17(9), 1209-1215 (2006)

27. Liu, Z.J., Cheng, S.J., Gailie, D.R., Julian, R.R.: Exploring the mechanism of selective noncovalent adduct protein probing mass spectrometry utilizing site-directed mutagenesis to examine ubiquitin. Anal. Chem. 80(10), 3846-3852 (2008)

28. Ly, T., Liu, Z.J., Pujanauski, B.G., Sarpong, R., Julian, R.R.: Surveying ubiquitin structure by noncovalent attachment of distance constrained bis(crown) ethers. Anal. Chem. 80(13), 5059-5064 (2008)

29. Sun, Q., Tyler, R., Volkman, B., Julian, R.: Dynamic interchanging native states of lymphotactin examined by SNAPP-MS. J. Am. Soc. Mass Spectrom. 22(3), 399-407 (2011)

30. Sakamoto, S., Kudo, K.: Supramolecular control of split-GFP reassembly by conjugation of beta-cyclodextrin and coumarin units. J. Am. Chem. Soc. 130(29), 9574-9582 (2008)

31. Chinai, J.M., Taylor, A.B., Ryno, L.M., Hargreaves, N.D., Morris, C.A., Hart, P.J., Urbach, A.R.: Molecular recognition of insulin by a synthetic receptor. J. Am. Chem. Soc. 133(23), 8810-8813 (2011)

32. Hwang, I., Baek, K., Jung, M., Kim, Y., Park, K.M., Lee, D.W., Selvapalam, N., Kim, K.: Noncovalent immobilization of proteins on a solid surface by cucurbit[7]uril-ferrocenemethylammonium pair, a potential replacement of biotin-avidin pair. J. Am. Chem. Soc. 129 (14), 4170-4171 (2007)

33. Escalante, M., Zhao, Y.P., Ludden, M.J.W., Vermeij, R., Olsen, J.D., Berenschot, E., Hunter, C.N., Huskens, J., Subramaniam, V., Otto, C.: Nanometer arrays of functional light harvesting antenna complexes by nanoimprint lithography and host-guest interactions. J. Am. Chem. Soc. 130(28), 8892-8893 (2008)

34. Talbiersky, P., Bastkowski, F., Klärner, F.-G., Schrader, T.: Molecular clip and tweezer introduce new mechanisms of enzyme inhibition. $J$. Am. Chem. Soc. 130(30), 9824-9828 (2008)

35. Sinha, S., Lopes, D.H.J., Du, Z., Pang, E.S., Shanmugam, A., Lomakin, A., Talbiersky, P., Tennstaedt, A., McDaniel, K., Bakshi, R., Kuo, P.Y., Ehrmann, M., Benedek, G.B., Loo, J.A., Klärner, F.-G., Schrader, T., Wang, C., Bitan, G.: Lysine-specific molecular tweezers are broadspectrum inhibitors of assembly and toxicity of amyloid proteins. $\mathrm{J}$. Am. Chem. Soc. 133(42), 16958-16969 (2011)

36. Rekharsky, M.V., Yamamura, H., Ko, Y.H., Selvapalam, N., Kim, K., Inoue, Y.: Sequence recognition and self-sorting of a dipeptide by cucurbit[6]uril and cucurbit[7]uril. Chem. Commun. 19, 2236-2238 (2008)

37. Heo, S.W., Choi, T.S., Park, K.M., Ko, Y.H., Kim, S.B., Kim, K., Kim, H.I.: Host-guest chemistry in the gas phase: Selected fragmentations of $\mathrm{cb}[6]$-peptide complexes at lysine residues and its utility to probe the structures of small proteins. Anal. Chem. 83(20), 7916-7923 (2011)

38. Roepstorff, P., Fohlman, J.: Proposal for a common nomenclature for sequence ions in mass-spectra of peptides. Biomed. Mass Spectrom. 11 (11), 601 (1984)

39. Plimpton, S.: Fast parallel algorithms for short-range moleculardynamics. J. Comput. Phys. 117(1), 1-19 (1995)

40. MacKerell, A.D., Bashford, D., Bellott, M., Dunbrack, R.L., Evanseck, J.D., Field, M.J., Fischer, S., Gao, J., Guo, H., Ha, S., JosephMcCarthy, D., Kuchnir, L., Kuczera, K., Lau, F.T.K., Mattos, C., Michnick, S., Ngo, T., Nguyen, D.T., Prodhom, B., Reiher, W.E., Roux, B., Schlenkrich, M., Smith, J.C., Stote, R., Straub, J., Watanabe, M., Wiorkiewicz-Kuczera, J., Yin, D., Karplus, M.: All-atom empirical potential for molecular modeling and dynamics studies of proteins. $J$. Phys. Chem. B 102(18), 3586-3616 (1998)

41. Becke, A.D.: Density-functional thermochemistry III. The role of exact exchange. J. Chem. Phys. 98(7), 5648-5652 (1993)

42. Lee, C.T., Yang, W.T., Parr, R.G.: Development of the Colle-Salvetti correlation-energy formula into a functional of the electron-density. Phys. Rev. B 37(2), 785-789 (1988)

43. Frisch, M.J., Trucks, G.W., Schlegel, H.B., Scuseria, G.E., Robb, M.A., Cheeseman, J.R., Scalmani, G., Barone, V., Mennucci, B., Petersson, G.A., Nakatsuji, H., Caricato, M., Li, X., Hratchian, H.P., Izmaylov, A.F., Bloino, J., Zheng, G., Sonnenberg, J.L., Hada, M., Ehara, M., Toyota, K., Fukuda, R., Hasegawa, J., Ishida, M., Nakajima, T., Honda, Y., Kitao, O., Nakai, H., Vreven, T., Montgomergy, J.A., Peralta, J.E., Ogliaro, F., Bearpark, M., Heyd, J.J., Brothers, E., Kudin, K.N., Staroverov, V.N., Kobayashi, R., Normand, J., Raghavachari, K., Rendell, A., Burant, J.C., Iyengar, S.S., Tomasi, J., Cossi, M., Rega, N., Millam, J.M., Klene, M., Knox, J.E., Cross, J.B., Bakken, V., Adamo, C., Jaramillo, J., Gomperts, R., Stratmann, R.E., Yazyev, O., Austin, A.J., Cammi, R., Pomelli, C., Ochterski, J.W., Martin, R.L., Morokuma, K., Zakrzewski, V.G., Voth, G.A., Salvador, P., Dannenberg, J.J., Dapprich, S., Daniels, A.D., Farkas, Ö., Foresman, J.B., Ortiz, J.V., Cioslowski, J., Fox, D.J.: Gaussian 09, Revision A.1. Gaussian, Inc, Wallingford CT (2009)

44. Konermann, L., Douglas, D.J.: Unfolding of proteins monitored by electrospray ionization mass spectrometry: A comparison of positive and negative ion modes. J. Am. Soc. Mass Spectrom. 9(12), 1248-1254 (1998)

45. Sokratous, K., Roach, L.V., Channing, D., Strachan, J., Long, J., Searle, M.S., Layfield, R., Oldham, N.J.: Probing affinity and ubiquitin linkage selectivity of ubiquitin-binding domains using mass spectrometry. $J$. Am. Chem. Soc. 134(14), 6416-6424 (2012)

46. Novak, P., Young, M.M., Schoeniger, J.S., Kruppa, G.H.: A top-down approach to protein structure studies using chemical cross-linking and Fourier transform mass spectrometry. Eur. J. Mass Spectrom. 9(6), 623-631 (2003)

47. Buschmann, H.J., Cleve, E., Mutihac, L., Schollmeyer, E.: The formation of alkali and alkaline earth cation complexes with cucurbit 6 uril in aqueous solution: a critical survey of old and new results. $J$. Incl. Phenom. Macrocycl. Chem. 65(3/4), 293-297 (2009)

48. Jansen, K., Buschmann, H.J., Wego, A., Dopp, D., Mayer, C., Drexler, H.J., Holdt, H.J., Schollmeyer, E.: Cucurbit[5]uril, decamethylcucurbit[5] uril and cucurbit[6]uril. Synthesis, solubility, and amine complex formation. J. Incl. Phenom. Macrocycl. Chem. 39(3/4), 357-363 (2001)

49. Skinner, O.S., McLafferty, F.W., Breuker, K.: How ubiquitin unfolds after transfer into the gas phase. J. Am. Soc. Mass Spectrom. 23(6), 1011-1014 (2012)

50. Lee, J.W., Samal, S., Selvapalam, N., Kim, H.J., Kim, K.: Cucurbituril homologues and derivatives: New opportunities in supramolecular chemistry. Acc. Chem. Res. 36(8), 621-630 (2003) 